\title{
DE SCHRIJFDOOS HET GELUID DER DINGEN
}

Toen de Meiji-keizer in 1912 na een regeerperiode van 45 jaar overleed, liet hij aan een van zijn hofdames een opmerkelijke schrijfdoos na. De schrijfdoos, die in 1909 aan de keizer was geschonken, toont de luitspeler en dichter Semimaru te midden van velden herfstbrem.

\section{Ontwerp}

Een oude man, gekleed in een hofkostuum dat zijn beste tijd gehad heeft, zit op de grond, de voeten ontbloot (afb. 1). De lucht die hem omringt is dampig, er dwarrelen rossige esdoornbladeren naar beneden: het is herfst. Het lijkt alsof hij zojuist zijn luitspel heeft onderbroken - hij houdt het plectrum immers nog in zijn rechterhand - om naar iets te luisteren. De geluiden eisen zijn volle aandacht op, zijn lichaam helt over in de richting waar ze vandaan komen. Wát hij hoort is nog niet duidelijk.

Toen ik deze grote schrijfdoos voor het eerst zag, ging er een schok door mij heen op het moment dat ik mij realiseerde dat de oude man blind is. Hij moest dan wel de blindgeboren Semimaru zijn, de in ongenade gevallen prins, die uit de hoofdstad Kyoto werd verbannen. In de bergen brengt alleen de luit (biwa) vertroosting in zijn eenzame en armoedige bestaan.

$\mathrm{Na}$ het openen van de schrijfdoos ontvouwen zich uitgestrekte velden van bloeiende herfstbrem (Lezpedeza bicolor Trucz. of hagi) (afb. 2). De volle maan staat laag boven de velden. Het moet hard geregend hebben want de planten liggen platgeslagen op de aarde. Ook hier is de lucht dampig. Hoever de velden herfstbrem zich uitstrekken, wordt duidelijk na het weghalen van het plankje dat de inktsteen en de waterdruppelaar draagt (hieronder bevindt zich de opbergplaats voor het papier). Ook op de binnenkant van de bodem zijn deze velden te zien, en wel op zo'n manier dat de velden een doorlopend geheel vormen wanneer de doos, het plankje voor de inktsteen en de binnenkant van het deksel naast elkaar worden gelegd. Het ontwerp is zelfs zover doorgevoerd dat niet alleen op de binnenzijde van de zijkanten van de doos, maar tevens op de zijkanten van de inktsteen herfstbrem te zien is, die in beide gevallen perfect aansluit op de herfstbrem van zowel de bodem als het plankje (afb. 3).

Afb. 1

Buitenaanzicht van de schrijfdoos Het geluid der dingen, $28,4 \mathrm{x}$ $19,2 \times 5,1 \mathrm{~cm}$., Japan, 1909, Rijksmuseum Amsterdam, inv.nr AK-C-2012-3. Bruikleen van Jan Dees en René van der Star.
$\mathrm{Nu}$ kunnen wij ons voorstellen wat Semimaru hoort: het geritsel van de wind in de struiken, druppelend water en het sjirpen van de krekels. Wellicht zullen deze geluiden hem inspireren bij zijn luitspel. Maar van de maan heeft hij geen weet.

Of Semimaru werkelijk heeft bestaan is twijfelachtig, maar de legende heeft beroemde toneelschrijvers als Zeami (1363-1443) en Chikamatsu Monzaemon (1653-1725) aangezet tot het schrijven van $N o \overline{-}$-stukken, waarvan sommige tot op de dag van vandaag worden opgevoerd. 

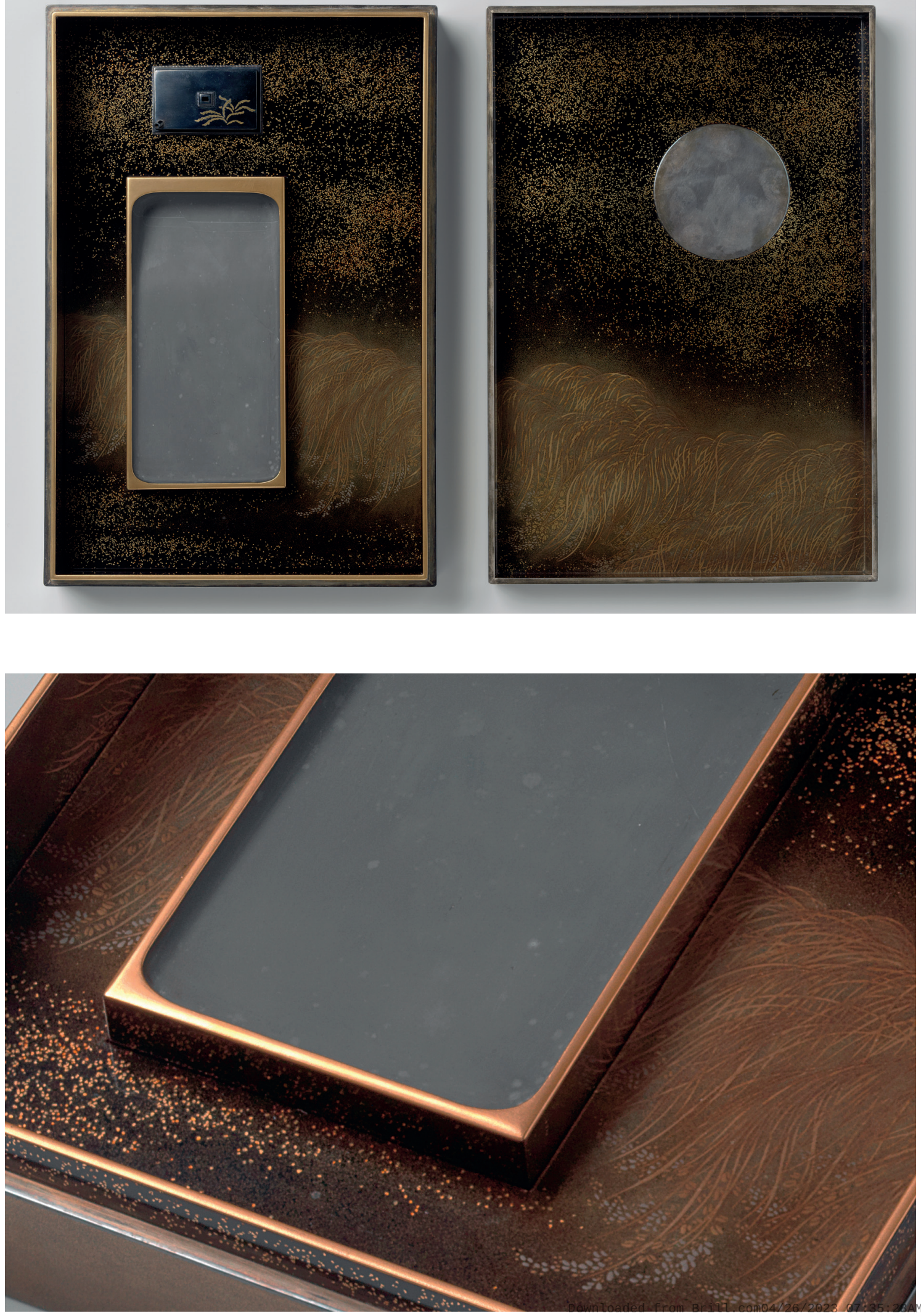
Afb. 2

Geopende schrijfdoos met inktsteen en waterdruppelaar.

Afb. 3

Detail van de geopende schrijfdoos, waarop te zien is dat het ontwerp van verregende herfstbremstruiken zich aan de binnenzijde voortzet op de zijkanten van de doos en zelfs op de zijkanten van de inktsteen.
De luitspeler op het deksel is uitgebeeld in hoogreliëf takamakie, met alleen de detailleringen, zoals de baard, in laagreliëf of hiramakie. Liefhebbers van Japans lak hebben vaak een uitgesproken voorkeur voor een briljant uitgevoerde 'uitgeslepen' decoratie in togidashi, maar een werkelijk sculpturale afbeelding in hoogreliëf vergt minstens zo veel vakmanschap (zie voor uitleg van de laktechnieken Aziatische Kunst 44/3 (2014): pp. 12-14 en afb. 4). Een close-up van Semimaru's gezicht laat zien hoe realistisch het resultaat van hoogreliëf lak kan zijn (afb. 4). Het reliëf is opgebouwd uit een aantal vullagen bestaande uit lak vermengd met gedroogde kleipoeder of houtskoolpoeder. Pas daar overheen werden de gouden laklagen aangebracht.

De maan is uit een plaatje zilver gezaagd, waarna de randen zijn afgewerkt en de schijf werd bevestigd op de lakondergrond. Hierna zijn wellicht nog enkele laklagen op de rest van de ondergrond aangebracht om de maan stevig vast te zetten en er iets in te laten verzinken.

De velden van herfstbrem zijn overal uitgevoerd in de 'uitgeslepen' togidashi techniek. Het gebruik van verschillende tinten goud heeft een enigszins schilderachtig effect teweeg gebracht.

De waterdruppelaar is gemaakt van de specifiek Japanse shakudo-legering, bestaande uit 95 procent koper vermengd met goud en zilver. Het blauwzwarte oppervlak werd verkregen door het voorwerp te koken in een zuurbad. In het shakudo oppervlak van de waterdruppelaar zijn twee schematische pluimen van het prachtriet in goud ingelegd.

De randen van zowel de doos als het deksel zijn voorzien van beschermende zilveren strips.

\section{De makers}

De houten verpakkingsdoos van deze schrijfdoos kan geen aanspraak maken op de naam tomobako - een samentrekking van tomo (vriend) en hako (doos) -, omdat de kunstenaar er geen signatuur op achtergelaten heeft. Daarom is het juister om hier het neutrale woord sotobako of buitendoos te gebruiken. Op de buitenkant van het deksel staat de titel Mono no ne suzuribako of schrijfdoos "Het geluid der dingen" vermeld. Daaraan wordt nog toegevoegd dat de schrijfdoos in de zevende maand van het $42^{\mathrm{e}}$ regeringsjaar van de Meiji-keizer (juli 1909) werd 'gebruikt' op een kunsttentoonstelling in Kyoto (Kyōto bijutsu kai). Dit betekent waarschijnlijk dat de keizer de schrijfdoos toen in gebruik heeft genomen en dat de doos bij die gelegenheid aan hem is geschonken (afb.5). Het is aannemelijk om te veronderstellen dat de schrijfdoos speciaal voor hem door een aantal kunstenaars is gemaakt. Zeker wanneer het een werk voor de keizer betrof werden de beste kunstenaars uitgenodigd om aan een dergelijk project, dat wel enkele jaren in beslag kon nemen, deel te nemen. In Kyoto was het bovendien niet ongewoon dat een ontwerper, zoals bijvoorbeeld Kishi Kōkei (1839-1922), de tekeningen leverde. Of dat ook hier het geval is geweest blijft onbekend. Het ontwerp zou dan moeten zijn uitgevoerd door enkele lakmeesters, een metaalbewerker en een houtbewerker. In deze omstandigheden was het ongebruikelijk dat de kunstenaars het werk of zelfs maar de houten verpakkingdoos signeerden. 
Afb. 4

Close-up van

Semimaru's gezicht in hoogreliëf takamakie.

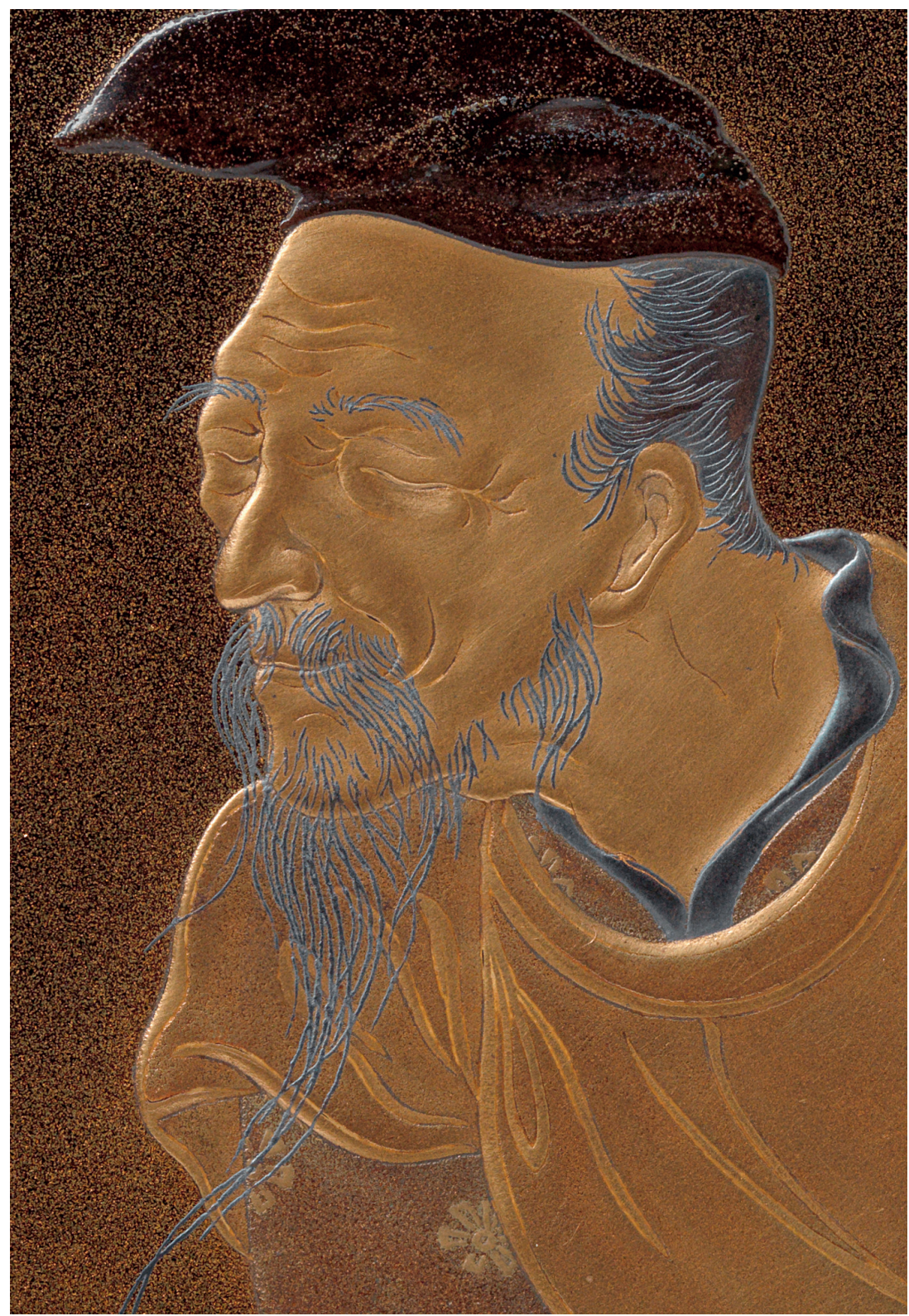

\section{Schenkers en ontvangers}

De Meiji-keizer heeft de schrijfdoos slechts drie jaar in zijn bezit gehad, aangezien hij in juli 1912 op 59-jarige leeftijd kwam te overlijden. Omdat hij enkele jaren tevoren nog een andere schrijfdoos (met een bijbehorende papierdoos) met het Semimaru-thema ten geschenke had gekregen zou men kunnen vermoeden dat de Meiji-keizer, Mutsuhito was zijn persoonlijke naam, een verwantschap met de blinde prins uit de legende voelde. Eén overeenkomst tussen hen is de voorliefde voor de dichtkunst, een andere wellicht het gevoel van isolement. De Meiji-keizer heeft honderdduizend gedichten nagelaten, waarin het gevoel van eenzaamheid in zijn hoge ambt een terugkerend thema is. 
Afb. 5 (links)

De Meiji-keizer op latere leeftijd. In 1909 werd de schrijfdoos aan hem geschonken en na zijn dood liet hij deze na aan hofdame Hirata Miei.

Afb. 6

Graaf Watanabe Chiaki, minister van de Keizerlijke Hofhouding, schreef de tekst op de binnenkant van de houten verpakkingsdoos.
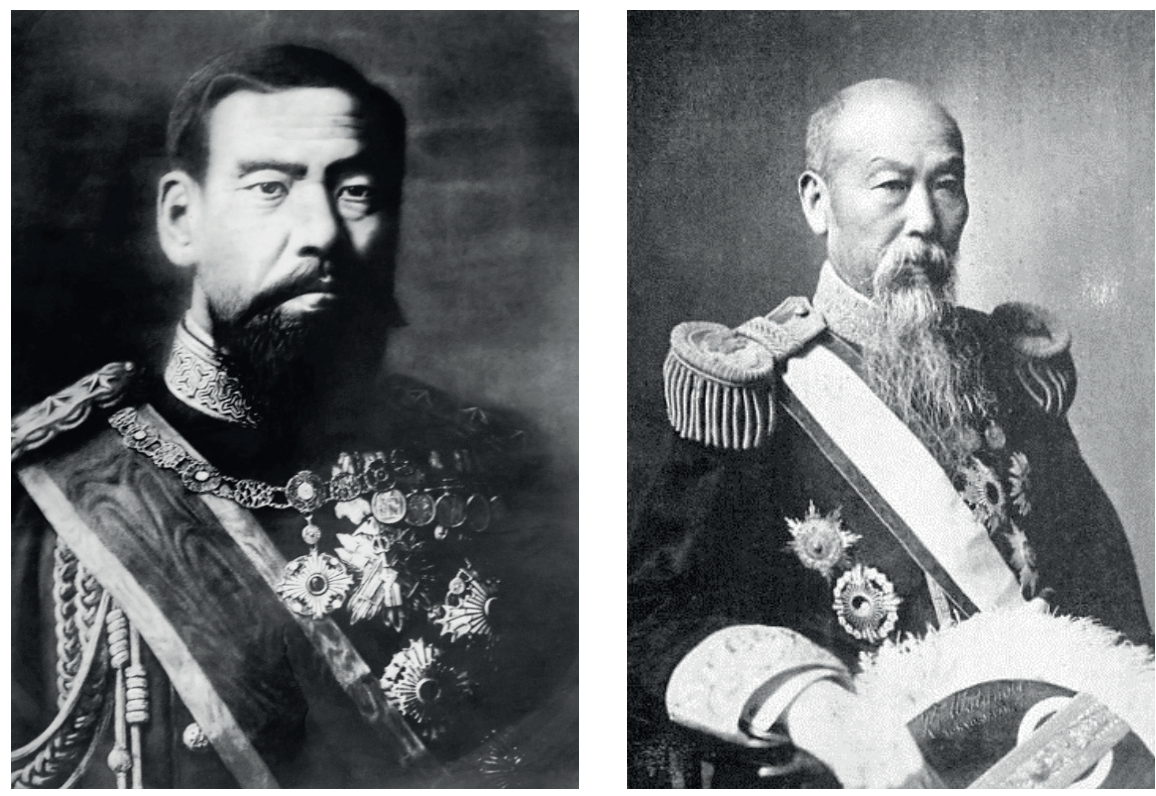

Op de binnenkant van de houten verpakkingsdoos staat nog een uitgebreide tekst, die geschreven is door graaf Watanabe Chiaki (1843-1921), de toenmalige minister van de Keizerlijke Hofhouding (Kunaishō) (afb. 6). Daarin valt te lezen dat de schrijfdoos Het geluid der dingen op last van de overleden keizer op de $29^{\mathrm{e}}$ dag van de $12^{\mathrm{e}}$ maand in het eerste regeringsjaar van de Taishō-keizer (29 december 1912) is geschonken aan Hirata Miei gon no myōbu (gon no myōbu is een hofrang). Op de binnenkant van de bodem zit bovendien een etiket geplakt met daarop de met de hand geschreven naam Hirata gon no myōbu.

Navraag bij de handelaar in Tokyo, die deze doos van haar familie had gekocht, leerde dat Hirata Miei de Meiji-keizer als concubine (gon no tenji) had gediend. Zou zij keizer Musuhito vertroosting hebben gebracht in eenzame uren, zoals de luit dat deed aan Semimaru? Anders had hij haar wel een schrijfdoos met kersenbloesem of met chrysanten nagelaten, of, indien zij een weemoedige natuur bezat, een kleine schrijfdoos met herfstplanten ...

- In 1975 is Jan Dees geboeid geraakt door de lakkunst van Japan. Naast zijn werk als gastro-enteroloog verricht hij sinds de late jaren 80 in Europa en Japan onderzoek naar lakkunstenaars uit de periode 1890 -1950. Hieruit is in 2007 het proefschrift Facing Modern Times: The revival of Japanese lacquer art 1890-1950 voortgekomen.

\section{Literatuur}

Jan Dees, 'De schrijfdoos Herfstplanten van Dōmoto Gosaburō', Aziatische Kunst 44/3 (2014), pp. 11-5.

Donald Keene, Emperor of Japan: Meiji and his World, 1852-1912, Columbia University Press, New York, 2002.

Susan Matisoff, The Legend of Semimaru, Blind Musician of Japan, Columbia University Press, New York, 1978. 


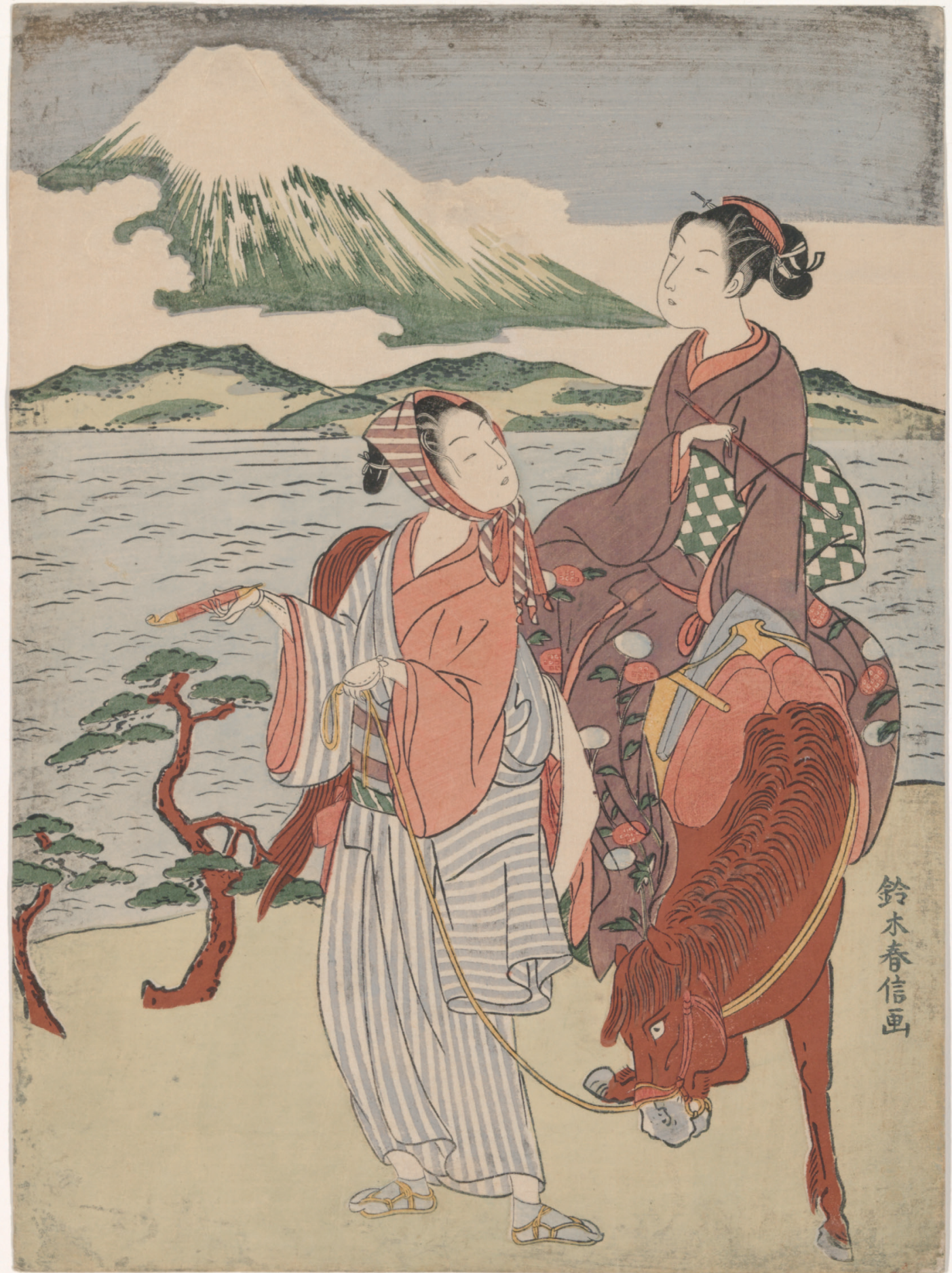

